\title{
Class II Box Consensus Sequences in the HLA-DR $\alpha$ Gene: Transcriptional Function and Interaction with Nuclear Proteins
}

\author{
PAULA A. SHERMAN, $\uparrow$ PATRICIA V. BASTA, TERRY L. MOORE, ADRIENNE M. BROWN \\ ,AND JENNY P.-Y. TING* \\ Lineberger Cancer Research Center and Department of Microbiology/Immunology, University of North Carolina, \\ Chapel Hill, North Carolina 27599
}

Received 23 May 1988/Accepted 4 October 1988

\begin{abstract}
The promoter regions of class II major histocompatibility complex genes contain two highly conserved sequences, the $X$ and $Y$ boxes, which may be involved in the control of class II gene expression. In this study, we correlate in vivo functional assays for cis-acting regulatory elements in the HLA-DR $\alpha$ gene with in vitro binding assays for trans-acting regulatory proteins. Mutagenesis and transient transfection analyses indicated that both the $X$ and $Y$ boxes were important for HLA-DR $\alpha$ promoter function in a B lymphoblastoid cell line. Although specific nuclear protein interactions with the $X$ consensus sequence were not apparent, the $Y$ box, which contained an inverted CCAAT sequence, did bind specifically to at least one nuclear protein. This $Y$ box-binding protein was present in nuclear extracts of all cell types examined, including human $B$ and $T$ cells and HeLa cells. The molecular mass of the protein, as determined by photoactivated protein-DNA crosslinking, was approximately 40 to 50 kilodaltons. Mutagenesis of the $\mathrm{Y}$ box that decreased protein binding also decreased promoter activity, implying that protein binding to this DNA sequence is important for DRa promoter function.
\end{abstract}

The class II major histocompatibility complex (MHC) antigens are cell surface glycoproteins that are critical determinants in immune system function. These molecules control the level of the immune response through their role in the presentation of antigen to class II-restricted, antigenspecific T cells (14). Class II antigen expression is subject to a complicated program of genetic controls, which varies with the cell type. Class II antigens are found primarily on immunocompetent cells, including B lymphocytes and macrophages (8). A wide variety of effectors, including gammainterferon, can regulate the level of class II gene expression (13).

DNA sequence comparisons have revealed that all human and murine class II genes possess two short, highly conserved sequences located in the region $5^{\prime}$ of the transcription start site (15). The length of the spacer region between the two consensus sequences is also highly conserved. These consensus sequences, referred to as the $\mathrm{X}$ and $\mathrm{Y}$ (or $\mathrm{A}$ and B) boxes, are putative cis-acting regulatory elements involved in the control of class II gene expression.

Our laboratory was the first to report that the class II boxes are required for promoter function in a human class II gene, HLA-DR $\alpha$, and that a DNA probe containing these consensus sequences binds to a nuclear protein that exhibits wide tissue distribution (16). We have now extended this investigation by determining that the specific sites of proteinDNA contact are contained in the $\mathrm{Y}$ box. Mutation of these contact sites reduces promoter activity, providing evidence that protein-Y box interactions are critical for DR $\alpha$ promoter function. Such a correlation between protein-DNA interaction sites and promoter activity has not been previously demonstrated for human class II MHC genes.

\footnotetext{
* Corresponding author.

$\dagger$ Present address: Experimental Therapy Department, Burroughs Wellcome Company, Research Triangle Park, NC 27709.
}

\section{MATERIALS AND METHODS}

Cells. Raji is a human Epstein-Barr virus-positive Burkitt's lymphoma cell line, HSB is a human T-leukemia cell line, and HeLa is a human cervical carcinoma cell line. All cells were cultured in RPMI 1640 medium supplemented with $10 \%$ fetal calf serum.

Transfected DNA. Deletion mutant $5^{\prime} \Delta-267$ contains approximately 300 base pairs (bp) of DNA $5^{\prime}$ to the cap site, the cap site, and 30 bp $3^{\prime}$ to the cap site of the HLA-DR $\alpha$ gene fused to the bacterial chloramphenicol acetyltransferase (CAT) gene (1). Deletion mutant $5^{\prime} \Delta-91$ is similar to $5^{\prime} \Delta-267$ but is lacking an additional $176 \mathrm{bp}$ of $5^{\prime}$-flanking sequence, including the $X$ box. Other plasmids were prepared as follows. pDRA1000, which contains $1,000 \mathrm{bp}$ of $\mathrm{DR} \alpha 5^{\prime}$ flanking sequence, was linearized with $\mathrm{XbaI}$, followed by exonuclease III (Stratagene) digestion for 2.5 and $3.0 \mathrm{~min}$, respectively, at $26^{\circ} \mathrm{C}$. Single-stranded DNA was removed with mung bean nuclease (Stratagene), followed by digestion with ClaI, treatment with Klenow enzyme to form blunt ends, addition of $\mathrm{XbaI}$ linkers, and religation. A deletion mutant in which both class II boxes were removed $\left(5^{\prime} \Delta-56\right)$ was characterized by dideoxy DNA sequence determination directly from the double-stranded plasmid DNA (21) with a 20-base single-stranded oligonucleotide complementary to a 5 ' CAT coding sequence (20) as a primer for reverse transcriptase. $5^{\prime} \Delta-56 \overline{\mathrm{X}+\mathrm{Y}}, 5^{\prime} \Delta-56 \overleftarrow{\mathrm{X}+\mathrm{Y}}, 5^{\prime} \Delta-56$ mut $1 \mathrm{X}, 5^{\prime} \Delta$ 56 mut $2 X$, and $5^{\prime} \Delta-56$ mut $Y$ were then obtained by linearizing 5' $\Delta$-56 with $X b a I$, followed by treatment with Klenow enzyme to form blunt ends, and insertion of a single copy of a 50-bp double-stranded oligonucleotide containing, respectively, wild-type $\mathrm{X}$ and $\mathrm{Y}$ boxes in both orientations, a mutated $X$ box and a wild-type $Y$ box, or a wild-type $X$ box and a mutated $Y$ box. 5' $\Delta-56 \mathrm{X}$ was prepared in a similar fashion, except that a 36-bp oligonucleotide containing only the $X$ box was inserted into $5^{\prime} \Delta-56$. Sequences of the resulting constructs were confirmed as just described.

pCH110, which contains the simian virus 40 early promoter fused to the bacterial $\beta$-galactosidase gene, was ob- 


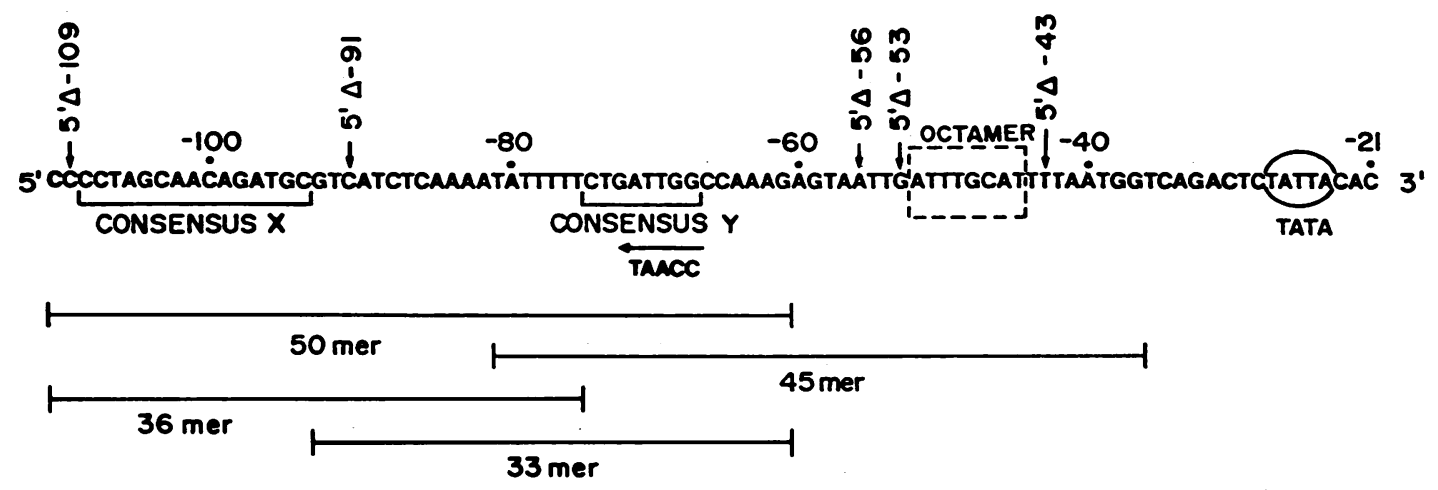

FIG. 1. Promoter region of the HLA-DR $\alpha$ gene. Nucleotides are numbered relative to the cap site. Potential cis-acting regulatory elements include the TATA box, the octamer motif ATTTGCAT, and the class II boxes (designated consensus X and consensus Y). As shown previously, a consensus CCAAT box is located on the opposite strand of the $Y$ box (16). The deletion mutants used in transfection analyses contained $\mathrm{DR} \alpha$ gene fragments extending from positions indicated by arrows above the sequence to $+30 \mathrm{bp}$. Locations of oligonucleotides used as probes in protein-DNA binding assays are shown below the sequence.

tained from Pharmacia. pSV2CAT is identical to the plasmid described by Gorman et al. (6).

Transfection. Raji cells were transiently transfected with the Biorad Gene Pulser electroporation apparatus; $10^{7}$ cells were collected by centrifugation and suspended in $0.3 \mathrm{ml}$ of complete RPMI. Five micrograms of DR $\alpha$-cat DNA and $1 \mu \mathrm{g}$ of pCH110 were added, and the cell suspension was pulsed at a voltage setting of $200 \mathrm{~V}$ and a capacitance setting of 960 $\mu \mathrm{F}$. The cells were immediately transferred to $10 \mathrm{ml}$ of complete RPMI. Approximately $48 \mathrm{~h}$ following transfection, cells were counted, harvested by centrifugation, washed once with phosphate-buffered saline, and suspended in 0.25 M Tris hydrochloride ( $\mathrm{pH}$ 7.6). The volume of extraction medium was proportional to the number of cells, usually 50 $\mu l$ per $10^{6}$ cells. Cells were then lysed by several freeze-thaw cycles, cellular debris was removed by centrifugation, and the resulting extracts were assayed for CAT activity (6) and $\beta$-galactosidase activity (9). Assay mixtures for CAT activity contained $25 \mu$ l of cellular extract, $0.175 \mathrm{M}$ Tris hydrochloride ( $\mathrm{pH} 7.6), 1 \mathrm{mM}$ acetyl coenzyme $\mathrm{A}$, and $0.1 \mu \mathrm{Ci}$ of $\left[{ }^{14} \mathrm{C}\right]$ chloramphenicol (New England Nuclear; specific activity, $55 \mathrm{mCi} / \mathrm{mmol}$ ) in a total volume of $180 \mu$ l. Assay mixtures for $\beta$-galactosidase activity contained $50 \mu \mathrm{l}$ of cellular extract, $150 \mu$ l of $\mathrm{Z}$ buffer $\left(0.1 \mathrm{M} \mathrm{NaPO}_{4}\right.$ [pH 7.0], 10 $\mathrm{mM} \mathrm{KCl}, 50 \mathrm{mM}$ 2-mercaptoethanol, $1 \mathrm{mM} \mathrm{MgSO}_{4}$ ) and 40 $\mu$ l of $o$-nitrophenyl- $\beta$-D-galactoside $(4 \mathrm{mg} / \mathrm{ml}$ in $0.1 \mathrm{M}$ $\mathrm{NaPO}_{4}$ ). Both assay mixtures were incubated overnight.

S1 nuclease analysis. S1 nuclease analysis was performed as described elsewhere (P. Basta, P. Sherman, and J. Ting, Proc. Natl. Acad. Sci. USA, in press). The probe was a uniformly labeled antisense RNA containing $295 \mathrm{bp}$ of the $\mathrm{DR} \alpha$ upstream region, including the start site, and $266 \mathrm{bp}$ of the CAT structural gene.

Electrophoretic mobility shift assay. The gel shift assay was performed as described previously (16), except that gels were dried before autoradiography.

Methylation interference analysis. This procedure was performed essentially as described before (18), except that the methylation reaction was carried out for $20 \mathrm{~min}$ at $25^{\circ} \mathrm{C}$ and DNA was isolated from mobility shift gels by overnight agitation of the crushed gel slices in $0.5 \mathrm{M}$ ammonium acetate. Products of the piperidine cleavage reactions were analyzed by electrophoresis through a $12 \%$ polyacrylamide$8 \mathrm{M}$ urea sequencing gel. If any of the methyl groups introduced by dimethylsulfate interfered with the binding of a specific protein, then that molecule of DNA would be missing in the complex band on the mobility shift gel and subsequently in the corresponding sequencing ladder.

Photoactivated protein-DNA cross-linking. A 50 -bp probe containing the $\mathrm{X}$ and $\mathrm{Y}$ boxes was prepared by annealing the non-coding strand of a 36-base oligonucleotide containing the $\mathrm{X}$ box with the coding strand of a 33-base oligonucleotide containing the $\mathrm{Y}$ box (Fig. 1). The 5 ' extensions were filled in by using dGTP, $\left[\alpha-{ }^{32} \mathrm{P}\right] \mathrm{dATP},\left[\alpha-{ }^{32} \mathrm{P}\right] \mathrm{dCTP}, 5$-bromo-dUTP, and Klenow enzyme. Binding reactions were as described in the legend to Fig. 2 for the mobility shift assay. Cross-linking and DNase I digestion were performed as described before (19). The samples were then mixed with loading buffer, boiled for $4 \mathrm{~min}$, and applied to a $10 \%$ polyacrylamidesodium dodecyl sulfate (SDS) gel. The wet gel was subjected to autoradiography.

\section{RESULTS}

Class II boxes are required for HLA-DR $\alpha$ promoter function. To investigate the transcriptional function of the class II boxes, we prepared a series of recombinant plasmids in which HLA-DR $\alpha$ promoter fragments were fused to the bacterial cat gene. The resulting constructs were either deletion mutants, in which the $\mathrm{X}$ or $\mathrm{Y}$ box (or both) was removed from the $\mathrm{DR} \alpha$ promoter, or substitution mutants, in which selected bases in the consensus sequences were altered. Accordingly, in $5^{\prime} \Delta-91$, the $X$ box was removed; in $5^{\prime} \Delta-56 X$, the $Y$ box was removed; and in $5^{\prime} \Delta-56$, both $X$ and $Y$ boxes were absent. In $5^{\prime} \Delta-56 \overline{X+Y}$, wild-type $X$ and $Y$ consensus sequences were present; in $5^{\prime} \Delta$-56mut $1 X$, every base in the $X$ consensus sequence was altered; in $5^{\prime} \Delta$ 56 mut $2 X$, the $X$ consensus sequence was altered at three of the most highly conserved bases; in $5^{\prime} \Delta$-56mutY, the $Y$ consensus sequence was altered at 5 bases determined by methylation interference analysis to be protein-DNA contact points (see below); and in $5^{\prime} \Delta-56 \overleftarrow{\mathrm{X}+\mathrm{Y}}$, wild-type $\mathrm{X}$ and $\mathrm{Y}$ boxes were present but in reverse orientation from that in $5^{\prime} \Delta-56 \overline{\mathrm{X}+\mathrm{Y}}$.

These constructs were introduced by electroporation into a B lymphoblastoid cell line, Raji, that constitutively expresses high levels of the HLA-DR $\alpha$ antigen. The results of transfections with deletion mutants are shown in Fig. 2, and the results for substitution mutants are shown in Table 1 . As previously reported (16), DR $\alpha$ promoter activity was observed with a mutant in which all flanking sequences 5 ' of the class II boxes were removed $\left(5^{\prime} \Delta-56 \overline{X+Y}\right)$. A construct 


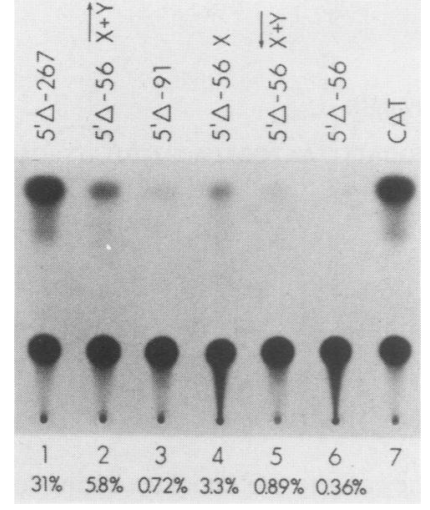

FIG. 2. Transfection of human B cells with DR $\alpha$ deletion mutants. Extracts of transfected cells were analyzed for CAT activity by thin-layer chromatography and autoradiography. The autoradiograph shows relative amounts of acetylated chloramphenicol reaction products. Lane 1, Plasmid 5' $\Delta-267$; lane 2, plasmid containing both $X$ and $Y$ boxes; lane 3, $X$ box deleted; lane 4, Y box deleted; lane 5 , both $X$ and $Y$ boxes present but in reverse orientation; lane 6 , both $X$ and $Y$ boxes deleted; lane 7 , reaction products obtained with a commercial preparation of CAT. The numbers below the lane markings are the calculated values for percent conversion of chloramphenicol to its acetylated forms, obtained by cutting out and counting sections of the plate.

which contained an additional 158 bp of 5 '-flanking sequence $\left(5^{\prime} \Delta-267\right)$ gave a CAT signal that was four to five times higher than the signal observed for $5^{\prime} \Delta-56 \overline{\mathrm{X}+\mathrm{Y}}$. This implies that positive transcriptional regulatory elements are located upstream of the class II boxes in the DR $\alpha$ gene; these elements have not yet been defined. Deletion of the $\mathrm{X}$ box reduced the activity of the DR $\alpha$ promoter by approximately $90 \%$ (Fig. 2, lane 3). However, alterations in the $\mathrm{X}$ consensus sequence (at every base or at only a few highly conserved bases) resulted in only a $30 \%$ loss of DR $\alpha$ promoter activity in our assay system (Table 1). Both deletion and substitution mutagenesis of the $\mathrm{Y}$ consensus sequence reduced promoter activity by approximately $50 \%$ (Fig. 2 , lane 4 , and Table 1 ). Reversing the orientation of the class II boxes resulted in a large decrease in promoter activity, as did deletion of both class II boxes. As a control for transfection efficiency, the plasmid $\mathrm{pCH} 110$ was cotransfected with each deletion mutant. Equivalent levels of $\beta$-galactosidase activity were observed in all transfections, indicating that differences in CAT

TABLE 1. Transfection of human B cells with DR $\alpha$ substitution mutants ${ }^{a}$

\begin{tabular}{|c|c|}
\hline $\mathrm{DR} \alpha-c a t$ recombinant & $\begin{array}{l}\text { Relative CAT } \\
\text { activity } \pm \text { SE }\end{array}$ \\
\hline 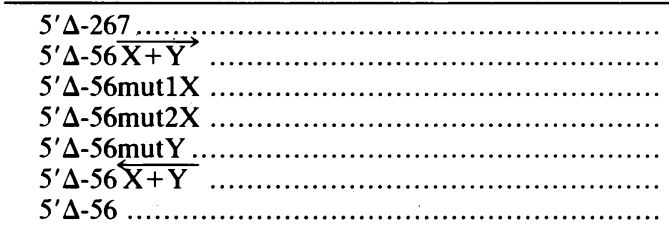 & $\begin{array}{c}4.00 \pm 0.28 \\
1.0 \\
0.66 \pm 0.04 \\
0.67 \pm 0.01 \\
0.51 \pm 0.03 \\
0.19 \pm 0.06 \\
0.22 \pm 0.07\end{array}$ \\
\hline
\end{tabular}

${ }^{a}$ Raji cells were transfected by electroporation. Extracts of transfected cells were analyzed for CAT activity by thin-layer chromatography and autoradiography. Conversion of chloramphenicol to its acetylated forms was quantified by cutting out and counting sections of the plates. The data are normalized to CAT activity measured for $5^{\prime} \Delta-56 \overrightarrow{\mathrm{X}+\mathrm{Y}}$ (construct containing both the $\mathrm{X}$ and $\mathrm{Y}$ consensus sequences) and are the average of three independent determinations $\pm \mathrm{SE}$. Recombinant plasmids are described in detail in Materials and Methods.

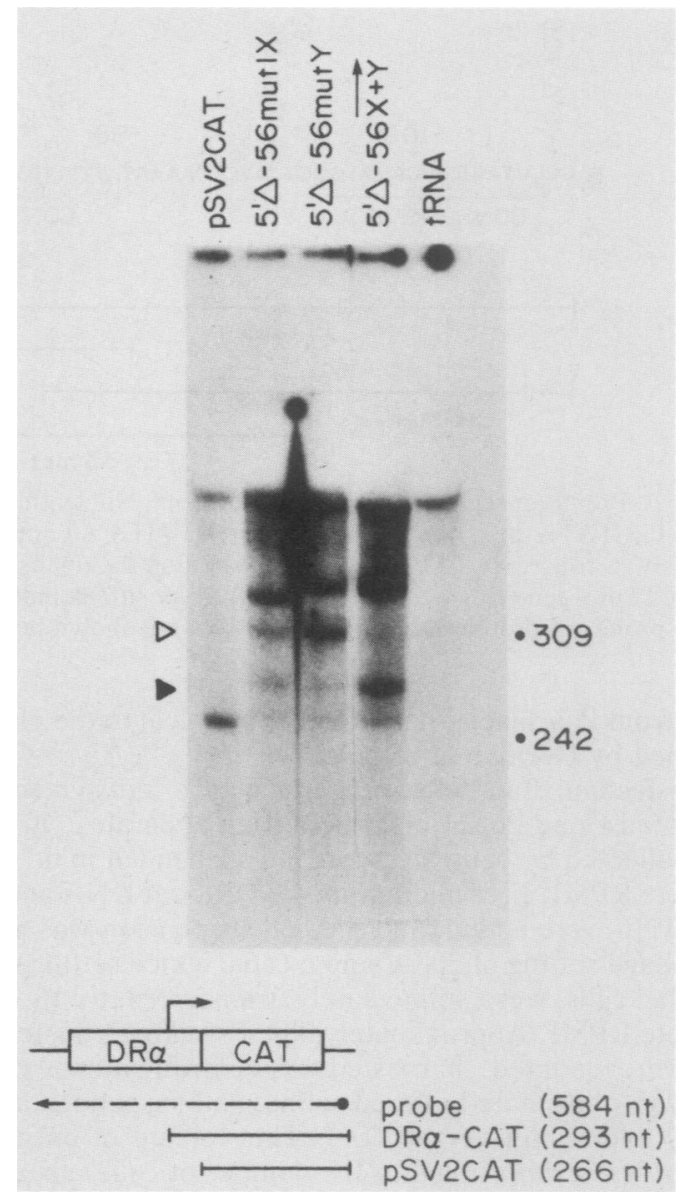

FIG. 3. S1 nuclease mapping of DR $\alpha$-cat transcription initiation sites. A $35-\mu \mathrm{g}$ (pSV2CAT, positive control) or 75- $\mu$ g (DR $\alpha$-cat constructs and tRNA, negative control) amount of total cellular RNA isolated from Raji cells tra..sfected with the indicated plasmids was hybridized with a ${ }^{32} \mathrm{P}$-labeled antisense RNA probe $(4--)$ containing 295 bp of DR $\alpha$ sequence, including the cap site and 266 bp of the cat structural gene. Hybrids were then digested with S1 nuclease, and digestion products were analyzed on a $6 \%$ denaturing polyacrylamide gel. Plasmids are described in detail in Materials and Methods. Predicted sizes of protected fragments are shown below the autoradiogram. $\triangleright$, Correctly initiated DR $\alpha$-cat transcripts: $D$. transcripts initiated at an upstream cap site unique to $X$ and $Y$ box mutants. Positions of molecular mass markers (in daltons) are indicated to the right of the autoradiogram. nt, Nucleotides.

activity were not due to differences in transfection efficiency (data not shown).

To assess the effect of mutagenizing the class II boxes on the accuracy of transcription initiation, cap sites for cat mRNAs produced in Raji cells transfected with $5^{\prime} \Delta-56 \overline{\mathrm{X}+\mathrm{Y}}$. $5^{\prime} \Delta-56$ mut $1 X$, and $5^{\prime} \Delta-56$ mutY were determined by $\mathrm{S} 1 \mathrm{nu}-$ clease mapping. As shown in Fig. 3, a correctly initiated transcript was observed for all three DR $\alpha$-cat recombinants. Substitution mutagenesis of the $\mathrm{X}$ or the $\mathrm{Y}$ box resulted in lower levels of this transcript. This is in agreement with the results from CAT analysis. Additional upstream and downstream cap sites were observed. Most notably, a transcript initiating from an upstream site was present in RNA from cells transfected with both class II box mutants, but was absent in cells transfected with $5^{\prime} \Delta-56 \overline{X+Y}$. This suggests that part of the CAT signal in cells containing $X$ and $Y$ box mutants may be due to aberrant transcription initiation. In a similar fashion, deletion of the $\mathrm{X}$ or the $\mathrm{Y}$ box in the $\mathrm{E}_{\alpha \kappa}$ gene 

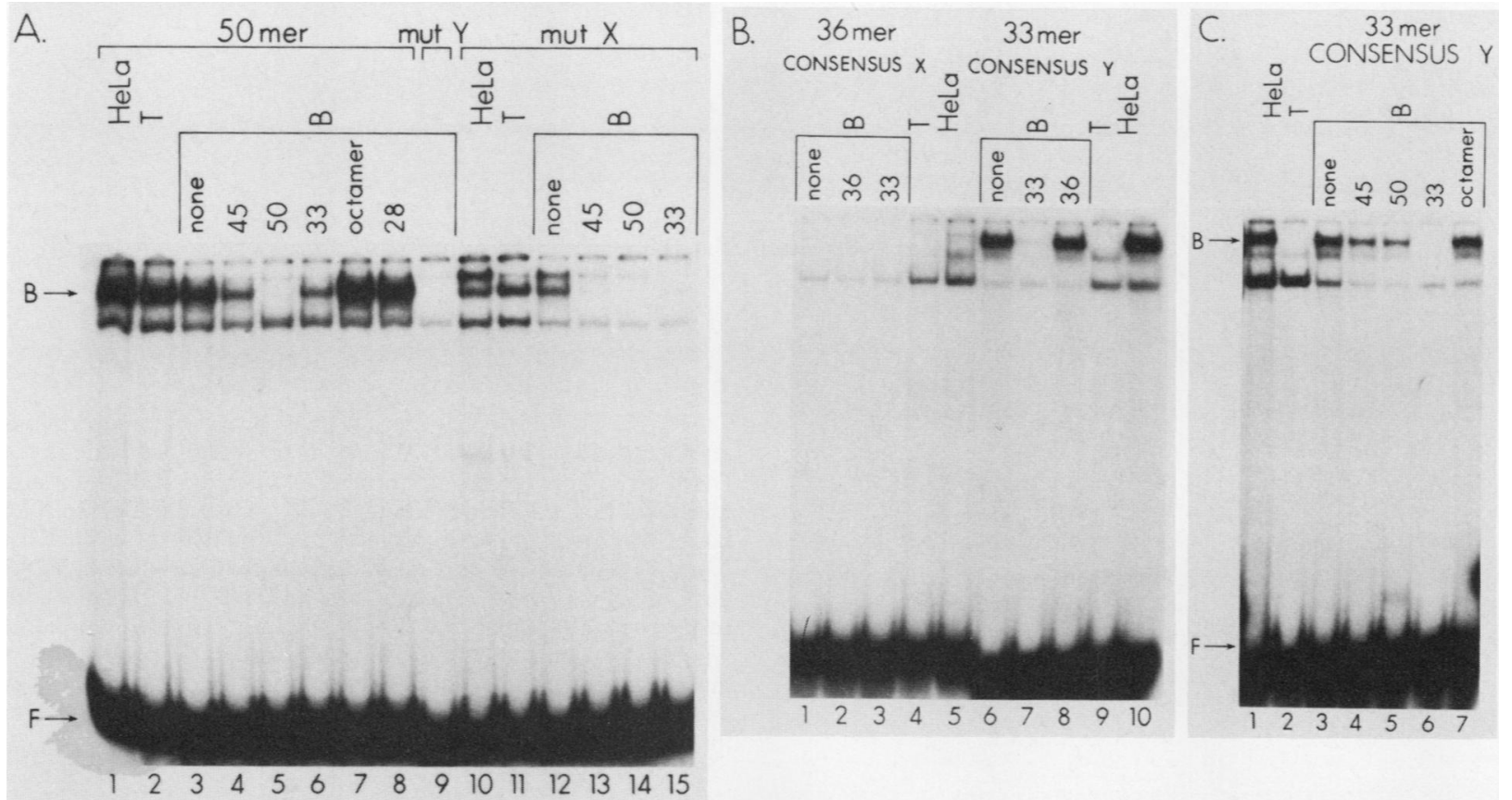

FIG. 4. Electrophoretic mobility shift assays of nuclear proteins binding to the class II boxes in the HLA-DR $\alpha$ gene. Binding reaction mixes contained $25 \mathrm{mM}$ HEPES (pH 7.9), $2.5 \mathrm{mM} \mathrm{MgCl}, 25 \mathrm{mM} \mathrm{NaCl}, 4 \mu \mathrm{g}$ of poly(dI-dC) - poly(dI-dC), $6 \mu \mathrm{g}$ of nuclear extract protein, and 1 to $2 \mathrm{ng}$ of labeled DNA probe in a total volume of $20 \mu \mathrm{l}$. As indicated above the lanes, $100 \mathrm{ng}$ of various unlabeled oligonucleotides were used as competitors in the binding assays. Nuclear extracts were prepared from HeLa cells, HSB cells, and Raji cells. (A) Proteins binding to wild-type and mutated class II boxes. Probes used were a 50-mer containing wild-type X and Y boxes (lanes 1-8); mut $Y$, a 50-mer containing a wild-type $X$ box and a mutated $Y$ box (lane 9); and mut $X$, a 50-mer containing a mutated $X$ box and a wild-type $Y$ box (lanes 10-15). The positions of a specific protein-DNA complex and free probe are indicated by arrows B and F, respectively. (B) Proteins binding to separate probes of the $\mathrm{X}(36-\mathrm{mer})$ and $\mathrm{Y}(33$-mer) boxes. $(\mathrm{C})$ Competition analysis of proteins binding to the $\mathrm{Y}$ box.

caused incorrect transcription initiation in transgenic mice (4).

Binding of nuclear proteins to class II boxes in the HLADR $\alpha$ gene. The high degree of sequence and positional conservation of the class II boxes, in combination with their functional requirement in $\mathrm{DR} \alpha$ gene expression (as demonstrated by our transfection data), suggests that these DNA sequences interact with sequence-specific transcription factors. DNA-binding proteins can be detected with an electrophoretic mobility shift assay, which is based on the retarded migration of protein-DNA complexes relative to free DNA during gel electrophoresis. The use of small DNA fragments as probes enhances the sensitivity and resolution of the assay (17). When we used a 50-bp synthetic oligonucleotide that contained both class II boxes as a probe in the mobility shift assay, we detected two predominant bands in nuclear extracts of all cell lines examined (Fig. 4A, lanes 1 to 3 ). A binding competition analysis was performed to establish the specificity of the complex formation. This analysis revealed that the faster-moving band was most likely due to a nonspecific interaction; the addition of a variety of specific and nonspecific competitors did not affect the formation of this complex (lanes 4 to 7). In contrast, an excess of unlabeled 50 -mer almost completely blocked the formation of the slower-moving complex, designated B (lane 5). A 45-mer and a 33-mer (both contained the Y consensus sequence; see Fig. 1) also competed with the 50-bp probe for the formation of complex B, but to a lesser extent than the 50-mer itself (lanes 4 and 6). An oligonucleotide containing the octamer consensus sequence ATTTGCAT (see Fig. 1 and discussion below), flanked by sequences unrelated to the DR $\alpha$ gene, and a 28-mer of completely unrelated sequence both had no effect on the formation of complex B (lanes 7 and 8).

To better define the protein-binding site(s) in the 50-mer, separate probes were prepared for the $X(36-\mathrm{mer})$ and $Y$ (33-mer) consensus sequences. No specific protein-DNA complexes were detected when the $\mathrm{X}$ consensus sequence was used as a probe in the mobility shift assay, with the possible exception of a weak complex observed in a HeLa cell extract (Fig. 4B, lanes 1 to 5). Since the failure to detect protein binding to the $X$ box could be due to the absence in the 36-mer of upstream sequences important for proteinDNA interaction, a new probe was prepared that contained an additional $31 \mathrm{bp}$ of upstream $\mathrm{DR} \alpha$ sequence. No new complexes were detected when this 67-bp probe was used in the mobility shift assay (data not shown).

Specific protein-DNA complexes (one predominant band and one less intense, faster-moving band) were detected with the $\mathrm{Y}$ consensus sequence-containing probe (Fig. 4B, lanes 6 to 8). Interestingly, the slower-moving complex was absent in a nuclear extract of HSB cells (T-cell line) (lane 9), but was present in nuclear extracts of all other cell types tested, including another T-cell line (data not shown). Additional competition analysis of the protein-DNA complexes detected with the 33-mer probe is shown in Fig. 3C. An excess of unlabeled 33-mer completely blocked the formation of both complexes (lane 6). The 45-mer and 50-mer also competed, but to a lesser extent than the 33-mer.

Further evidence that the $\mathrm{Y}$ box is the primary site of protein binding in the 50 -mer was obtained by preparing a 50 -mer with a mutated $\mathrm{Y}$ consensus sequence; as in the case of $5^{\prime} \Delta-56$ mut $Y$ used in the functional analysis (Table 1 ), the 


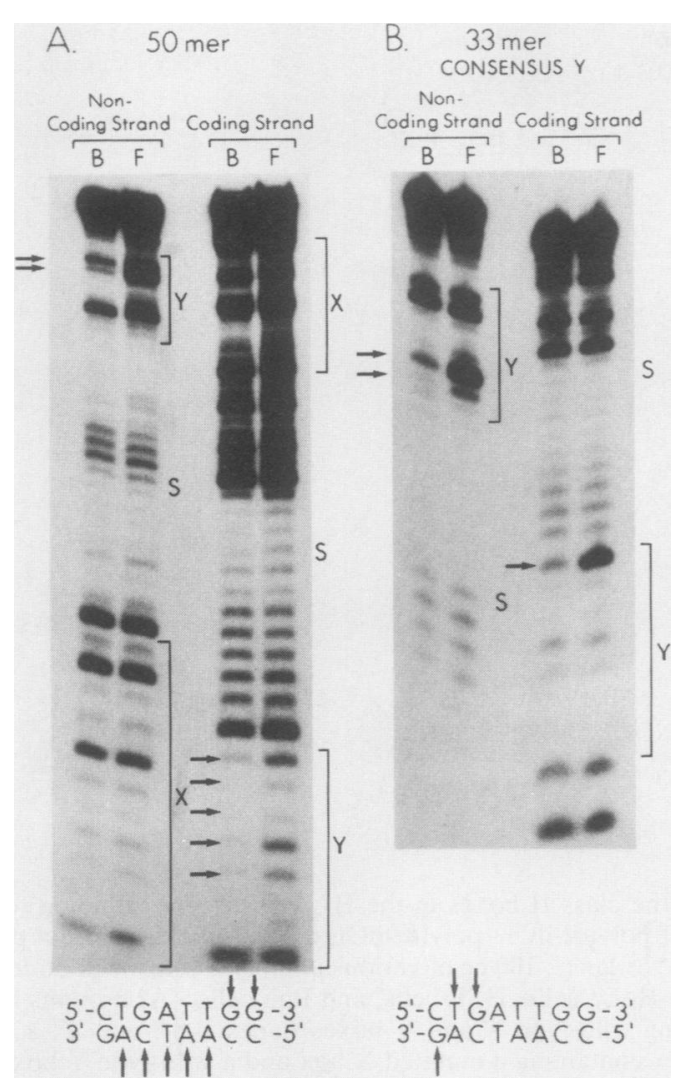

FIG. 5. Methylation interference analysis. (A) 50-mer used as a probe. (B) 33-mer ( $\mathrm{Y}$ box) used as a probe. Locations of $\mathrm{X}$ box, spacer region (S), and $\mathrm{Y}$ box are indicated. The arrows designate residues at which methylation specifically interfered with protein binding. Lanes: B, bound DNA; F, free DNA.

sequence CTGATTGG was changed to CGGAGGTT. As mentioned above, these mutations were chosen to alter the $\mathrm{Y}$ consensus sequence at protein-DNA contact points. When this new oligonucleotide (designated mut $Y$ ) was used as a probe in the mobility shift assay, complex B was absent (Fig. 4A, lane 9).

Similarly, the role of the $\mathrm{X}$ box was analyzed by preparing a 50-mer with a mutated $X$ consensus sequence that was identical to the sequence in $5^{\prime} \Delta-56$ mut $1 \mathrm{X}$. When this probe (designated mutX) was used in the mobility shift assay, the formation of complex B and the pattern of competition by different oligonucleotides were similar to those with the wild-type 50-mer (Fig. 4A, lanes 10 to 15 ). This suggests that conservation of the $\mathrm{X}$ consensus sequence is not required for the formation of complex B. A novel complex that migrated more slowly than complex B was observed with the mutX oligonucleotide in B-cell and HeLa cell extracts and at a much reduced level in a T-cell (HSB) extract. Formation of this complex was effectively blocked by three different oligonucleotides (50-mer, 45-mer, and 33-mer) that contained the $\mathrm{Y}$ box.

Methylation interference analysis of protein-DNA complexes. To further delineate the site(s) of nuclear protein binding in the 50-mer, we performed a methylation interference analysis. The results of this experiment are shown in Fig. 5A. In agreement with the mobility shift data, the most clearly defined protein-DNA contact points in the 50-mer were located within the 8-bp Y consensus sequence. This methylation interference pattern was very similar to the

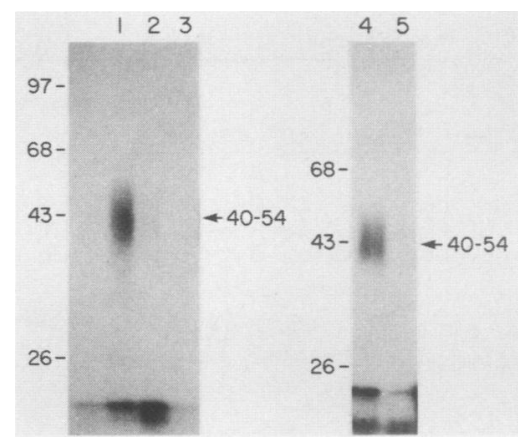

FIG. 6. Size determination of class II box-binding proteins by photoactivated protein-DNA cross-linking. Photoactivated proteinDNA cross-linking was performed as described in Materials and Methods. Lanes 1 and 4, ${ }^{32} \mathrm{P}$-labeled 50-mer containing the $\mathrm{X}$ and $\mathrm{Y}$ boxes was cross-linked to proteins in a Raji nuclear extract. Lanes 2 and 3, Same as lanes 1 and 4 except that the cross-linking was performed in the presence of 50- and 100-fold molar excesses, respectively, of unlabeled 50-mer. Lane 5, 50-mer containing a wild-type $\mathrm{X}$ and a mutated $\mathrm{Y}$ box was used as a probe. Molecular mass markers (in kilodaltons) are to the left of the autoradiogram, and the estimated molecular mass of the DNA-binding protein is indicated to the right.

pattern observed for protein interactions with the $\mathrm{Y}$ box from the $E_{\alpha}$ gene (3). The hint of an interference pattern in the $\mathrm{X}$ consensus sequence and spacer region of the coding strand was not reproducible.

The predominant complex observed in mobility shift assays with the 33-mer probe was also subjected to methylation interference analysis. The faster-migrating complex was of low abundance and therefore was not analyzed further. As shown in Fig. 5B, removing the upstream $X$ consensus sequence yielded a methylation interference pattern different from the pattern obtained for the 50-mer. The proteinbinding site was still contained within the $\mathrm{Y}$ consensus sequence but appeared to be shifted in a $5^{\prime}$ direction. This difference in methylation interference patterns and the differential distribution among cell types noted above (protein binding to the 50-mer was present in extracts of HSB cells but protein binding to the 33-mer was not) suggests that the two probes could be binding to different proteins.

Curiously, if the $\mathrm{X}$ consensus sequence was changed to a completely different sequence instead of removed (as in $5^{\prime} \Delta-56$ mut $\left.1 X\right)$, the methylation interference pattern for the protein binding to the $\mathrm{Y}$ consensus sequence was indistinguishable from that observed for the wild-type 50-mer (data not shown).

Size determination of the $\mathbf{Y}$ box-binding protein by photoactivated protein-DNA cross-linking. The approximate size of the class II box-binding polypeptide was determined by photoactivated protein-DNA cross-linking. A 50-mer containing the $\mathrm{X}$ and $\mathrm{Y}$ boxes was labeled with bromodeoxyuridine and ${ }^{32} \mathrm{P}$ and cross-linked by $\mathrm{UV}$ irradiation to proteins in Raji nuclear extracts. The protein-DNA complexes were then treated with DNase and resolved by electrophoresis. Since the size of the DNA fragment that remains attached to protein after DNase treatment is usually negligible compared with the size of the protein, the molecular weight of the protein-DNA complex approximates the size of the protein moiety alone.

A predominant protein species of 40 to 54 kilodaltons ( $\mathrm{kDa}$ ) formed a complex with the 50-mer (Fig. 6). A 50- or 100 -fold excess of unlabeled 50-mer effectively competed with the radiolabeled probe (Fig. 6, lanes 1 to 3), demon- 
strating that formation of the protein-DNA complex was specific. In addition, no complex formation was observed with a 50-mer containing a mutated $\mathrm{Y}$ box (described in Table 1), confirming that the protein was interacting with the $\mathrm{Y}$ box (Fig. 6, lanes 4 and 5).

\section{DISCUSSION}

In this study, we have attempted to correlate in vivo functional assays for cis-acting regulatory elements in the HLA-DR $\alpha$ gene with in vitro binding assays for trans-acting regulatory proteins. Our mutagenesis and transfection data indicate that the class II box consensus sequences are important for HLA-DR $\alpha$ promoter function. Analysis of protein-DNA binding shows that the $Y$ box specifically binds to at least one nuclear protein. Most important, mutagenesis of the $\mathrm{Y}$ box that decreases protein binding also decreases promoter activity, implying that protein binding to this sequence is important for promoter function.

Although we previously reported that removal of the $X$ consensus sequence by deletion mutagenesis $\left(5^{\prime} \Delta-91\right.$, Fig. 1) resulted in an almost complete loss of $\mathrm{DR} \alpha$ promoter function (16), in the current study we found that seemingly gross alterations in the base sequence of the $X$ box produced a smaller decrease in promoter activity. The difference in the results obtained with deletion mutagenesis and substitution mutagenesis may be explained by inherent differences between the two approaches. However, the inability to detect any strong protein complexes with the $X$ consensus sequence is in line with the apparent weak activity of this sequence as a transcriptional regulatory element. There have been several reports of specific protein interactions with the $X$ consensus sequence in class II genes $(4,10,12)$. The apparent absence of a strong $X$ box-binding protein in our assay system may be attributed to the low abundance of this protein, to the instability of the protein-DNA complex, and to differences in conditions for nuclear extract preparation and mobility shift analysis. Interestingly, Dorn et al. have also observed weak protein-DNA interactions with the mobility shift assay and a probe similar to ours that contains the $X$ consensus sequence from the murine $E_{\alpha}$ gene (4).

We have demonstrated specific nuclear protein interactions with the $Y$ consensus sequence. As we have noted previously (16), the $Y$ box contains a CCAAT box in reverse. Hence, the nuclear factor which binds to the $Y$ consensus sequence may be categorized as a CCAAT boxbinding protein. Removing the $X$ consensus sequence appears to alter protein binding to the $\mathrm{Y}$ consensus sequence, as determined by methylation interference analysis. In contrast, altering every base in the $\mathrm{X}$ sequence had no effect on the protein-DNA contact points in the $Y$ consensus sequence. Further study will therefore be required to determine the role, if any, of the $\mathrm{X}$ box in protein interactions at the Y box.

The protein that interacts with the class II boxes, most likely the $\mathrm{Y}$ box, was examined by photoactivated proteinDNA cross-linking. This procedure has been useful for estimating the sizes of a number of DNA-binding proteins. By our estimates, there is a predominant protein moiety of 40 to $54 \mathrm{kDa}$ that forms a complex with the $\mathrm{Y}$ box. Using three independent methods, Hooft van Huijsduijnen et al. reported two values for the molecular weight of a protein or protein complex that binds to the $Y$ box of the murine $E_{\alpha}$ gene (7). Two of the methods which did not employ denaturing or reducing conditions yielded mass estimates of greater than $200 \mathrm{kDa}$. A third method, in which proteins were analyzed on an SDS-polyacrylamide gel, indicated that the $\mathrm{Y}$ box-binding protein was in the $50-$ to $70-\mathrm{kDa}$ size range. This latter value is in good agreement with our mass estimate for the $\mathrm{Y}$ box-binding protein.

In addition to the class II boxes, the HLA-DR $\alpha$ gene contains an octanucleotide sequence (ATTTGCAT), located $14 \mathrm{bp}$ downstream of the $\mathrm{Y}$ consensus sequence (Fig. 1). The octamer motif is an essential transcriptional regulatory element in a wide variety of eucaryotic promoters, including the immunoglobulin light- and heavy-chain gene promoters $(2,5$, 11). The HLA-DR $\alpha$ gene may be unique among class II genes in that the octamer sequence is not found in the promoters of any other human or murine $\alpha$ - and $\beta$-chain genes sequenced to date. The murine $\mathrm{E}_{\alpha}$ gene does have a similar sequence (CTTTGGAT) at a location identical to the location of the HLA-DR $\alpha$ octamer sequence. We have previously reported an analysis of nuclear protein interactions with the DR $\alpha$ octamer (16), and we have also established that the octamer sequence is important for DR $\alpha$ promoter function (P. Sherman and J. P.-Y. Ting, manuscript in preparation). The presence of the octamer in the HLA-DR $\alpha$ promoter could contribute to differences in transcriptional regulatory mechanisms between the $\mathrm{DR} \alpha$ gene and other class II genes. For example, it is likely that interactions occur between proteins binding to the octamer and a protein(s) binding to the class II boxes in the HLA$\mathrm{DR} \alpha$ gene promoter.

\section{ACKNOWLEDGMENTS}

This work was supported by National Institutes of Health grant CA-42771-01, National Multiple Sclerosis Society grant RG-1785-A1, and North Carolina Biotechnology Center grant 87-G-01010.

We thank Jane Radford and Elizabeth Craig for preparation of the manuscript.

\section{ADDENDUM IN PROOF}

Since this paper was submitted, we have found that different batches of poly $(\mathrm{dI}-\mathrm{dC}) \cdot$ poly $(\mathrm{dI}-\mathrm{dC})$ affect protein binding to the $\mathrm{X}$ box. When one specific batch (Pharmacia, lot number QF817880) of poly(dI-dC) - poly(dI-dC) was used, protein-DNA complexes with the 36-mer were detected.

\section{LITERATURE CITED}

1. Basta, P. V., P. A. Sherman, and J. P.-Y. Ting. 1987. Identification of an interferon- $\gamma$ response region $5^{\prime}$ of the human histocompatibility leukocyte antigen $\mathrm{DR} \alpha$ chain gene which is active in human glioblastoma multiforme lines. J. Immunol. 138: $1275-1280$

2. Bergman, Y., D. Rice, R. Grosschedl, and D. Baltimore. 1984. Two regulatory elements for immunoglobulin $\kappa$ light chain gene expression. Proc. Natl. Acad. Sci. USA 81:7041-7045.

3. Dorn, A., J. Bollekens, A. Staub, C. Benoist, and D. Mathis. 1987. A multiplicity of CCAAT box-binding proteins. Cell 50: 863-872.

4. Dorn, A., B. Durand, C. Marfing, M. LeMeur, C. Benoist, and D. Mathis. 1987. Conserved major histocompatibility complex class II boxes $\mathrm{X}$ and $\mathrm{Y}$ are transcriptional control elements and specifically bind nuclear proteins. Proc. Natl. Acad. Sci. USA 84:6249-6253.

5. Falkner, F. G., and H. G. Zachau. 1984. Correct transcription of an immunoglobulin $\kappa$ gene requires an upstream fragment containing conserved sequence elements. Nature (London) 310:7174.

6. Gorman, C. M., L. F. Moffat, and B. H. Howard. 1982. Recombinant genomes which express chloramphenicol acetyltransferase in mammalian cells. Mol. Cell. Biol. 2:1044-1051. 
7. Hooft van Huijsduijnen, R. A. M., J. Bollekens, A. Dorn, C. Benoist, and D. Mathis. 1987. Properties of a CAAT box-binding protein. Nucleic Acids Res. 15:7265-7285.

8. Kaufman, J. F., C. Auffray, A. J. Korman, D. A. Shackelford, and J. Strominger. 1984. The class II molecules of the human and murine major histocompatibility complex. Cell 36:1-13.

9. Miller, J. H. 1972. Experiments in molecular genetics, p. 352355. Cold Spring Harbor Laboratory, Cold Spring Harbor, N.Y.

10. Miwa, K., C. Doyle, and J. L. Strominger. 1987. Sequencespecific interactions of nuclear factors with conserved sequences of human class II major histocompatibility complex genes. Proc. Natl. Acad. Sci. USA 84:4939-4943.

11. Queen, C., and J. Stafford. 1984. Fine mapping of an immunoglobulin gene activator. Mol. Cell. Biol. 4:1042-1049.

12. Reith, W., S. Satola, C. Herrero Sanchez, I. Amaldi, B. Lisowska-Grospierre, C. Griscelli, M. R. Hadam, and B. Mach. 1988. Congenital immunodeficiency with a regulatory defect in MHC class II gene expression lacks a specific HLA-DR promoter binding protein, RF-X. Cell 53:897-906.

13. Rosa, F., and M. Fellous. 1984. The effect of gamma-interferon on MHC antigens. Immunol. Today 5:261-262.

14. Rosenthal, A. S., and E. Shevach. 1973. Function of macrophages in antigen recognition by guinea pig $\mathrm{T}$ lymphocytes. J. Exp. Med. 138:1194-1212.

15. Saito, M., R. A. Maki, L. K. Clayton, and S. Tonegawa. 1983.
Complete primary structures of the $E \beta$ chain and gene of the mouse major histocompatibility complex. Proc. Natl. Acad. Sci. USA 80:5520-5524.

16. Sherman, P. A., P. V. Basta, and J. P.-Y. Ting. 1987. Upstream DNA sequences required for tissue-specific expression of the HLA-DR $\alpha$ gene. Proc. Natl. Acad. Sci. USA 84:4254-4258.

17. Singh, H., R. Sen, D. Baltimore, and P. A. Sharp. 1986. A nuclear factor that binds to a conserved sequence motif in transcriptional control elements of immunoglobulin genes. Nature (London) 319:154-158.

18. Staudt, L. M., H. Singh, R. Sen, T. Wirth, P. A. Sharp, and D. Baltimore. 1986. A lymphoid-specific protein binding to the octamer motif of immunoglobulin genes. Nature (London) 323: 640-643.

19. Treisman, R. 1987. Identification and purification of a polypeptide that binds to the c-fos serum responsive element. EMBO J. 6:2711-2717.

20. Walker, M. D., T. Edlund, A. M. Boulet, and W. J. Rutter. 1983. Cell-specific expression controlled by the 5 '-flanking region of insulin and chymotrypsin genes. Nature (London) 306: 557-561.

21. Zagursky, R. J., K. Baumeister, N. Lomax, and M. C. Berman. 1985. Rapid and easy sequencing of large linear double-stranded DNA and supercoiled plasmid DNA Gene. Anal. Technol. 2:8994. 